\title{
External cephalic version at 36 weeks and its outcome
}

\author{
Deepika N. ${ }^{1 *}$, Arun Kumar ${ }^{2}$ \\ ${ }^{1}$ Department of Obstetrics Gynaecology, MVJ Medical College and Research Hospital, Hoskote, Bangalore, \\ Karnataka, India \\ ${ }^{2}$ Department of Gynaecology, Civil Hospital, Sunni, Shimla, Himachal Pradesh, India
}

Received: 09 August 2017

Revised: 29 August 2017

Accepted: 04 September 2017

\author{
*Correspondence: \\ Dr. Deepika N., \\ E-mail: deepikang@gmail.com
}

Copyright: (C) the author(s), publisher and licensee Medip Academy. This is an open-access article distributed under the terms of the Creative Commons Attribution Non-Commercial License, which permits unrestricted non-commercial use, distribution, and reproduction in any medium, provided the original work is properly cited.

\section{ABSTRACT}

Background: External cephalic version (ECV) is well known non-invasive procedure done for the management of breech presentation but is not routinely practised by obstetricians in many clinical settings. The aim of the study was to assess the success rate of external cephalic version, labour outcome of pregnancy after successful ECV, to study maternal and foetal complications associated with ECV and to explore the reasons for failed ECV.

Methods: It was a prospective interventional study to assess the labour outcomes of pregnancies with successful and uncomplicated ECV. All women who had singleton breech presentation at $36+$ weeks were included unless contraindications for ECV were present. After obtaining consent, ECV was attempted after giving tocolysis.

Results: The total number of deliveries was 6038 in the same period. Out of these 301 were breech presentations thus the incidence of breech presentation was $4.9 \%$. ECV was offered to 81 women $(26.9 \%)$ and out of these 77 women $(95.06 \%)$ gave consent for the procedure. The remaining $4(4.93 \%)$ did not give consent due to anxiety about the procedure. The success rate was $54.54 \%$. Out of total 301 women with breech presentation 40 women (13.3\%) had assisted breech delivery and 216 women $(71.8 \%)$ had caesarean section due to obstetric indications. Thus the caesarean section rate for breech presentation at our institute was $71.8 \%$. ECV was successful in $63.82 \%$ of the multigravida on which it was attempted as compared to $40 \%$ of the primigravida. The success rate of ECV in the present study is maximum when ECV was performed at a gestational age of 38-39 weeks and when fetal weight was less than 3000 grams. Out of the 42 successful ECV cases, 4 babies $(9.52 \%)$ had neonatal sepsis and 1 was still born $(2.3 \%)$ which was unrelated to ECV.

Conclusions: ECV is a valuable though under used option in the management of breech presentation at term. It is a relatively safe procedure, simple to learn and perform. Vigilance for breech presentation after 36 weeks is important. $\mathrm{ECV}$ at term using tocolytics should be part of the routine management of breech presentation.

Keywords: Breech, Caesarean section, External cephalic version, Tocolysis

\section{INTRODUCTION}

External cephalic version has apparently been practiced since the time of Aristotle $(384-322 b c)$, who stated that many of his fellow authors advised midwives who were confronted with a breech presentation to "change the figure and place the head so that it may present at birth". ${ }^{1}$ Version is a procedure in which the fetal presentation is altered by physical manipulation either substituting one pole of a longitudinal presentation for the other or convert an oblique or transverse lie into a longitudinal presentation.

Breech presentation complicates $3-4 \%$ of all term deliveries and a higher proportion of preterm deliveries. The practice of allowing trial of labour for breech infants 
has been abandoned, with more than $80 \%$ of breech infants currently delivered by caesarean section. The caesarean rate in breech pregnancies increased from $15 \%$ in 1970 to $84 \%$ in 1989 , and breech presentation currently accounts for $10-15 \%$ of all caesareans. ${ }^{2}$ To stem this rise in the caesarean rate, Royal college of obstetricians and gynaecologists (RCOG) recommends that all women with uncomplicated breech should be offered ECV at term.

When a breech presentation is recognized prior to labour in a woman who has reached 36 weeks gestation, external cephalic version should be considered. Before this time there is relatively high incidence of recurrence. After 36 weeks the likelihood of spontaneous version is low. Moreover if version results in need for immediate delivery complications of iatrogenic preterm delivery generally are not severe.

The aim of the following prospective study was to assess the success and safety of ECV and labour outcomes following successful ECV.

\section{METHODS}

This interventional prospective study was carried out in the Department of Obstetrics and Gynaecology, Kamla Nehru Hospital for mother and child, Indira Gandhi Medical College Shimla for a period of one year from 01.06. 2013 to 31.05.2014.

\section{Study design}

It was a prospective interventional study to success and safety of ECV and labour outcomes of pregnancies with successful and uncomplicated ECV.

\section{Selection of patients}

In this study women with a singleton fetus in breech presentation and a gestational age of 36 weeks or more were eligible. Cases of breech presentation $<36$ weeks and >40 weeks period of gestation, breech in labour, previous uterine scar, pre-existing medical disorders, pregnancy induced hypertension/preeclampsia, gestational glucose intolerance, multiple gestation, severe oligohydramnios or polyhydramnios (amniotic fluid index $[\mathrm{AFI}]<5$ or $>25$ ), cases with any contraindication to vaginal delivery, intrauterine growth restriction, fetal anomalies and uterine malformations, placenta previa and abruptio placenta have been excluded from the study.

A detailed history of all the eligible women was enquired according to the proforma. Her obstetric and menstrual history was recorded. Data regarding her general physical examination and obstetric examination was recorded. Investigations such as haemoglobin, blood group, urine for albumin and sugar, glucose challenge test were taken note of. Any other investigations deemed necessary was recorded. An ultrasound examination was performed to confirm breech position, determine the AFI, note the placental location, rule out congenital anomalies and the presence of nuchal cord. All cases were counselled and an informed consent was taken for their inclusion in the study. The patient was asked to empty her bladder. A non-stress test was performed to confirm the absence of foetal heart rate abnormalities. Tocolysis of injection ritodrine $10 \mathrm{mg}$ was administered intramuscularly. The patient was placed in a slight trendelenburg position to facilitate disengagement/mobility of the breech. ECV performed and after the procedure, a non-stress test and ultrasound examination were performed to exclude foetal bradycardia and to confirm successful version. Rho (D) immuglobulin was administered after the procedure to all Rh-negative patients.

The primary outcome was successful ECV confirmed using ultrasound

The secondary outcome to be considered was

- Feto-maternal complications from ECV.

- Cephalic presentation at delivery.

- Mode of delivery, operative interference if any, caesarean section with its indication.

- The outcome of the foetus, gestational age at the time of delivery, its birth weight, Apgar at 1 and 5 minutes was recorded.

- Newborns shifted in the nursery, their details and treatment imparted was recorded.

- Maternal and foetal condition at the time of discharge was noted.

Data collected was analysed at the end of the study.

\section{RESULTS}

A total of 301 pregnant patients with breech presentation presented to the hospital during the study period. The total number of deliveries was 6038 in the same period. The incidence of breech presentation was $4.9 \%$.

A total of $77 \mathrm{ECV}$ was performed during the study period out of which $42(54.54 \%)$ were successful and 35 $(45.45 \%)$ cases were unsuccessful (Table 1$)$.

Table 1: Outcome of external cephalic version.

\begin{tabular}{|lll|}
\hline ECV attempted & Total no. of cases & $\%$ \\
\hline Successful & 42 & 54.54 \\
\hline Failed & 35 & 45.45 \\
\hline Total & 77 & 100 \\
\hline
\end{tabular}

Of the successful ECV cases, 35 (83.3\%) had vaginal delivery and $7(16.7 \%)$ had caesarean delivery for various indications. Out of 35 failed ECV cases, 32 (91.4\%) had elective caesarean section and $3(8.6 \%)$ had assisted breech delivery (Table 2). 
Table 2: Mode of delivery.

\begin{tabular}{|llll|}
\hline ECV & $\begin{array}{l}\text { Mode of } \\
\text { attempted }\end{array}$ & $\begin{array}{l}\text { No. of } \\
\text { cases }\end{array}$ & $\%$ \\
\hline \multirow{2}{*}{ Successful } & Vaginal delivery & 35 & 83.3 \\
\cline { 2 - 4 } & Emergency LSCS & 7 & 16.7 \\
\hline Failed & Elective LSCS & 32 & 91.4 \\
\hline & Trial of breech & 3 & 8.6 \\
\hline
\end{tabular}

Table 3 shows the outcome of ECV in relation to maternal age. Maternal age appeared to have significant bearing on the success rate of ECV. In women who were less than 20 years of age, ECV was attempted on 34 of them and it was successful in $20(58.82 \%)$. In women between 20-35 years age group the success rate of ECV was $39.39 \%$ and in women more than 35 years of age the success rate was $90 \%$.

The success rate was significantly higher in women more than 35 years of age as compared to the younger age group $(\mathrm{p}=0.005)$.

The effect of parity on the success of ECV is shown in Table 4. ECV was successful in $63.82 \%$ of the multigravida on which it was attempted as compared to $40 \%$ of the primigravida. The result was statistically significant $(\mathrm{p}=0.041)$.

Table 3: Outcome of ECV success in relation to maternal age.

\begin{tabular}{|c|c|c|c|c|c|c|}
\hline Age in years & $<20$ & $20-35$ & $>35$ & P value & & \\
\hline $\begin{array}{l}\text { Total ECV attempted } \\
(\mathrm{n}=77)\end{array}$ & 34 & 33 & 10 & $\begin{array}{l}<20 \text { vs } 20-35 \\
\text { age group }\end{array}$ & $\begin{array}{l}<20 \text { vs. }>35 \\
\text { age group }\end{array}$ & $\begin{array}{l}20-35 \text { vs. }>35 \\
\text { age group }\end{array}$ \\
\hline Successful ECV $(n=42)$ & 20 & 13 & 9 & \multirow[b]{2}{*}{0.112} & \multirow[b]{2}{*}{0.067} & \multirow[b]{2}{*}{0.005} \\
\hline $\begin{array}{l}\text { Percentage of successful } \\
\text { ECV }(\%)\end{array}$ & 58.82 & 39.39 & 90 & & & \\
\hline
\end{tabular}

Table 4: Outcome of ECV success in relation to parity.

\begin{tabular}{|c|c|c|c|}
\hline Parity & Primigravida & Multigravida & P value \\
\hline Total ECV attempted $(n=77)$ & 30 & 47 & \multirow{3}{*}{0.041} \\
\hline Successful ECV $(n=42)$ & 12 & 30 & \\
\hline Percentage of successful ECV (\%) & 40 & 63.82 & \\
\hline
\end{tabular}

Among the total 77 women on whom ECV was attempted 50 had upper and posterior placenta and 27 had upper and anterior placenta. In the women with upper and anterior placenta the success rate of ECV is $37.03 \%$ as compared to $64 \%$ in those with upper and posterior placenta. The $p$ value was 0.023 and statistically significant as shown in Table 5.
It was observed in the present study that when ECV was performed at $36-37$ weeks the success rate was $48.9 \%$ as compared to $42.9 \%$ at $37-38$ weeks, $87.5 \%$ at $38-39$ weeks, $83.3 \%$ at $39-40$ weeks and $50 \%$ when ECV was performed after 40 weeks of gestation as shown in table 6.

Table 5: Outcome of ECV success in relation to placental localisation on ultrasound.

\begin{tabular}{|c|c|c|c|}
\hline Placental localisation & Upper and posterior placenta & Upper and anterior placenta & P value \\
\hline Total ECV attempted $(n=77)$ & 50 & 27 & \multirow{3}{*}{0.023} \\
\hline Successful ECV $(n=42)$ & 32 & 10 & \\
\hline Percentage of successful ECV (\%) & 64 & 37.03 & \\
\hline
\end{tabular}

Table 6: Relation of ECV success to gestational age at which it was performed.

\begin{tabular}{|lllll|l|}
\hline Period of gestation & $36-37$ weeks & $37-38$ weeks & $38-39$ weeks & $39-40$ weeks & $>40$ weeks \\
\hline Total ECV attempted(n=77) & 47 & 14 & 8 & 6 & 2 \\
\hline Successful ECV $(\mathrm{n}=42)$ & 23 & 6 & 7 & 5 & 1 \\
\hline Percentage of successful ECV (\%) & 48.9 & 42.9 & 87.5 & 83.3 & 50 \\
\hline
\end{tabular}


Table 7: Relation of ECV success to gestational age at which it was performed ( $p$ value).

\begin{tabular}{|l|l|}
\hline Gestational age (in weeks) & P values \\
\hline 36-37 vs. $37-38$ & 0.689 \\
\hline 36-37 vs. $38-39$ weeks & $0.043^{*}$ \\
\hline 36-37 vs. $39-40$ weeks & 0.112 \\
\hline 36-37 vs. $>40$ weeks & 0.976 \\
\hline 37-38 vs. 38-39 weeks & $0.040^{*}$ \\
\hline 37-38 vs. 39-40 weeks & 0.095 \\
\hline 37-38 vs. >40 weeks & 0.849 \\
\hline 38-39 vs. $39-40$ weeks & 0.825 \\
\hline 38-39 vs. $>40$ weeks & 0.236 \\
\hline 39-40 vs. $>40$ weeks & 0.346 \\
\hline
\end{tabular}

*Statistically significant
It was seen that when ECV success rate was compared amongst each group it was significantly higher in group with gestational age 38-39 weeks as compared to both 36-37 weeks group and 37-38 weeks group ( $\mathrm{p}$ value 0.043 and 0.040 respectively) (Table 7 ). The type of breech and its relation to outcome of procedure is shown in Table 8. In complete breech presentation, the success rate was $65.95 \%$ as compared to $36.66 \%$ in incomplete breech. Success rate of ECV was thus significantly higher with flexed/complete breech $(p=0.012)$. In the group of women in whom EFW was between 2500-3000 grams the success rate of ECV was $74 \%$ as compared to $18.51 \%$ in women with EFW of more than 3000 grams. It was observed that success rate of ECV was significantly higher when fetal weight was less than 3000 grams $(\mathrm{p}<0.0001)$ as shown in Table 9.

Table 8: Outcome of ECV success with type of breech.

\begin{tabular}{|c|c|c|c|}
\hline Type of breech & Complete breech & Incomplete breech & P value \\
\hline Total ECV attempted(n=77) & 47 & 30 & \multirow{3}{*}{0.012} \\
\hline Successful ECV(n=42) & 31 & 11 & \\
\hline Percentage of successful ECV (\%) & 65.95 & 36.66 & \\
\hline
\end{tabular}

Table 9: Relation of estimated foetal weight on ultrasound parameters with ECV success.

\begin{tabular}{|c|c|c|c|}
\hline Estimated foetal weight & 2500-3000 grams & $>3000$ grams & P value \\
\hline Total ECV attempted(n=77) & 50 & 27 & \multirow{3}{*}{$<0.0001$} \\
\hline Successful ECV(n=42) & 37 & 5 & \\
\hline Percentage of successful ECV (\%) & 74 & 18.51 & \\
\hline
\end{tabular}

Of the total 42 cases in successful ECV group 37 women $(88.1 \%)$ went into spontaneous labour and 5 women $(11.90 \%)$ did not go into spontaneous labour and thus were induced at 40 weeks. $35(83.3 \%)$ had normal vaginal delivery and 7 patients $(16.7 \%)$ had emergency caesarean section. In the 7 patients who underwent caesarean section, indication was non-reassuring fetal status in 5 patients $(71.42 \%)$ and for non-progress of labour in 2 patients $(28.57 \%)$.

Out of total 42 successful ECV, maximum babies weighed between 2500-3000 grams. 4 babies (9.52\%) had neonatal sepsis and 1 was still born (2.3\%). The index case was a primigravida at period of gestation 36 weeks 6 days with no antenatal complications. ECV was attempted at 36 weeks 6 days and the primary outcome was successful. Since the policy at our institute was to admit the women eligible for ECV for the procedure and thereafter till delivery this patient went home against the advice and came at 38 weeks with loss of fetal movements. Intrauterine fetal death (IUFD) was diagnosed on ultrasound at admission and vaginal delivery was conducted. On delivery two loops of nuchal cord were found. The birth weight was 3200 grams and there was no evidence of gross congenital malformation or growth restriction. Autopsy was not performed because parents did not give consent for it.

33 women $(78.6 \%)$ were discharged with the baby within 3 days of delivery, 5 were discharged within 3-5 days $(11.9 \%)$ with no maternal and neonatal complications. However 4 had to stay for more than 5 days because of neonatal sepsis.

\section{DISCUSSION}

External cephalic version effectively reduces the rates of breech presentation and caesarean section in women with breech at term. It has been estimated that every $100 \mathrm{ECV}$ attempts there will be reduction of 34 cases of vaginal breech delivery and 16 cases of caesarean section for breech. ${ }^{9}$ The success rate of ECV in the present study was $54.54 \%$. This is comparable to $50-60 \%$ success rate in most studies. ${ }^{3-5}$ The ECV success rate was more $(94.2 \%)$ in the study by Abercombie because in this study the sample size was very small (ECV was attempted on 16 
women). ${ }^{6}$ In the study by Wibool et al intravenous terbutaline in the dosage of $0.3-0.5 \mathrm{mg}$ was used which resulted in better tocolysis and there was no reversion to breech after successful ECV leading to a success rate of $71.43 \%$. $^{7}$

Among the women who had successful ECV, vast majority $(83.3 \%)$ had normal vaginal delivery as compared to $16.7 \%$ who had caesarean delivery, and this is very important as the main purpose of ECV procedure is to avoid the possible complications that are associated with the two other options that may be chosen for the management of breech presentation at term which are elective caesarean section or vaginal breech delivery. The vaginal delivery rate in the successful ECV group in our study is comparable to the study by Healey et al with $89 \%$ normal vaginal delivery rate. ${ }^{8}$

Many prognostic factors for successful ECV have been identified and some authors have even devised a scoring system to predict the likelihood of successful version. ${ }^{10}$

Our study showed that parity has a very strong influence on the success of ECV. The success rate of multipara was $63.8 \%$ as compared to $40 \%$ for primipara and the increase is statistically significant and can be attributed to lower uterine and abdominal tone with multiparity. The results regarding the success rate of ECV in relation to parity in the studies by Impey et al, Hindawi, Wing et al, Azlin et al, Yong et al were also comparable to our study. ${ }^{11-15}$

Maternal age appeared to have significant bearing on the success rate of ECV. The reason is because all women were multiparas in this age group and high parity is associated with complete breech presentation and lower abdominal and uterine tone thus facilitating the version.

This is in contrast to the study by Arif et al in which the ECV was maximum successful in the age group of 20-35 years probably because maximum patients belonged to this age group. ${ }^{16}$

When the association between placental site and successful ECV was studied, we found that ECV was more likely to succeed in patients with a posterior rather than anterior placenta as posterior placenta causes less hindrance in moving the fetus during ECV and there is more ease in holding and manipulating the fetal head. Similarly Healey et al reported a success rate of $47 \%$ with upper and posterior placenta as compared to upper and anterior placenta. ${ }^{17}$

The success rate of ECV in the present study is maximum when ECV was performed at a gestational age of 38-39 weeks because the sample size was very small (only 8 women). Similarly only 6 women belonged to $39-40$ weeks. Secondly as the mean birth weight in the present study was between 2500-3000 grams as compared to 3200 grams in the study by Wibool et al, gestational age alone cannot be considered as a predictor of ECV success and is confounded by other factors such as birth weight.

This is in contrast to the studies by Wibool et al in which two groups were studied that is less than 39 weeks and $39-40$ weeks. $^{7}$ The success rate was $73.08 \%$ in less than 39 weeks group as compared to $50 \%$ in whom ECV was performed between 39-40 weeks.

Our observations regarding the success rate of ECV in relation to gestational age also differed from the results of Aisenbrey et al in which there was a success rate of $70 \%$ in women when ECV was performed at less than 37 weeks as compared to $29 \%$ when ECV was performed between 37-40 weeks. ${ }^{18}$ Success rate of version decreased with increase in gestational age in both these studies. The reason is because with advancing gestational age the amniotic fluid decreases and size of baby increases and the breech gets engaged as well.

For the type of breech, a frank breech is more difficult to convert to cephalic presentation due to reduced mobility because of extended legs and early engagement as shown in the present study with a success rate of $36.60 \%$ in incomplete breech as compared to $65.95 \%$ in complete breech. Similarly in the study by Aisenbrey et al the success rate of ECV was $74 \%$ in complete breech as compared to $29 \%$ in incomplete breech. ${ }^{18}$

In the present study the success rate of ECV was $74 \%$ in women having an EFW of 2500-3000 grams and it reduced to $18.51 \%$ with the $\mathrm{EFW}$ more than 3000 grams. A big baby is difficult to manipulate and must be the reason for above mentioned finding.

Aisenbrey et al however showed no difference in the success rate of ECV as compared to EFW as all the ECVs were performed by the author himself thus associated with high physician skill and experience, tocolytic (terbutaline $250 \mathrm{mg}$ ) was used and women were placed in 10 degree trendelenberg position before the procedure to disengage the breech and facilitate version. ${ }^{18}$

\section{CONCLUSION}

It was concluded that ECV is a valuable though under used option in the management of breech presentation at term. It is a relatively safe procedure, simple to learn and perform. Vigilance for breech presentation after 36 weeks is important. A proper understanding of the risk is essential for the obstetrician to allow accurate counselling.

All well-equipped obstetric units should offer ECV to suitable woman at term with breech presentations to produce considerable cost savings in the management of the breech fetus at term and can reduce maternal morbidity and mortality from surgery. ECV at term using tocolytics should be part of the routine management of breech presentation. 
Funding: No funding sources

Conflict of interest: None declared

Ethical approval: The study was approved by the Institutional Ethics Committee

\section{REFERENCES}

1. Carlos O, Steven L. A Randomised placebocontrolled evaluation of terbutaline for external cephalic version. Obstet Gynecol. 1997;90:775-9.

2. Gifford DS, Keeler E, Kahn KL. Reductions in cost and caesarean rate by routine use of external cephalic version: A decisionanalysis. Obstet Gynecol. 1995;85:930-6.

3. Baker PN, Kenny LC: Antenatal obstetric complications. In: Obstetrics by Ten teachers. 19th edition. Hodder and Stoughton Ltd; 2011: 95-101.

4. External cephalic version and reducing the incidence of breech presentation. Royal College of Obstetricians and Gynaecologists Guideline No. 20a. December 2006.

5. Richard H. Breech presentation. In Obstetrics and Gynaecology. An evidence-based text for MRCOG. In: David ML, Philip NB, editors. 1st edition. Oxford: Charon Tec Pvt. Ltd; 2004:413-426.

6. Abercrombie GF. The timing of external version. Proceedings Royal Society Med. 1957;51:163.

7. Wibool R. Efficacy of External Cephalic Version with Tocolysis in Late Pregnancy. J Med Assoc Thai. 2008;91(1):19-24.

8. Healey M, Porter R, Galimberti A. Introducing external cephalic version at 36 weeks or more in a district general hospital: a review and an audit. $\mathrm{Br} \mathrm{J}$ Obstet Gynaecol. 1997;104:1073-9.
9. Hofmeyer GJ. External cephalic version at term: How high are the stakes? Br J Obstet Gynecol. 1991;98:1-3.

10. Newman RB, Peacock BS, VanDorsten JP, Hunt $\mathrm{HH}$. Predicting success of external cephalic version. Am J Obstet Gynecol. 1993;169:245-9.

11. Impey L, Lissoni D. Outcome of external cephalic version after 36 weeks gestation without tocolysis. J Maternal-Fetal Med. 1999;8(5):203-7.

12. Hindawi I. Value and pregnancy outcome of external cephalic version. WHO Health J. 2005:11.

13. Myerscough $P$. The practice of external cephalic version. Br J Obstet Gynecol. 1998;105:1043-5.

14. Nor Azlin HI, Haliza H, Mahdy ZA, Anson I, Fahya MN, Jamil MA. Tocolysis in term breech external cephalic version. Int J Gynaecol Obstet. 2005;88:5-8.

15. Stephen PY. Introducing external cephalic version in a Malaysian Setting. Hong Kong Med J. 2007;13:405.

16. Arif W. Outcome of external cephalic version in terms of success rate and fetomaternal complications. ANNALS. 2010;16:64-8.

17. Healey M, Porter R, Galimberti A. Introducing external cephalic version at 36 weeks or more in a district general hospital: a review and an audit. $\mathrm{Br} \mathbf{J}$ Obstet Gynecol. 1997;104:1073-9.

18. Aisenbrey GA, Catanzarite VA, Nelson C. External cephalic version: predictors of success. Obstet Gynecol. 1999;94:783-6.

Cite this article as: Deepika N, Kumar A. External cephalic version at 36 weeks and its outcome. Int $\mathrm{J}$ Reprod Contracept Obstet Gynecol 2017;6:4602-7. 